\title{
A Study on the Application of the Extended Matrices Based on TRIZ in Constructing a Collaborative Model of Enterprise Network
}

\author{
Yan Yang ${ }^{1}$, Yunfei Shao ${ }^{1}$, and Xiaowo Tang ${ }^{2}$ \\ ${ }^{1}$ School of Management and Economics, University of Electronic Science and \\ Technology of China, Chengdu, 610054, China \\ ${ }^{2}$ Sichuan Province Education Office \\ \{Yan.Yang, Yunfei.Shao, Xiaowo.Tang, glxyxs\}@uestc.edu.cn
}

\begin{abstract}
Based on mass related literature on enterprise network, the key influence factors are reduced to Trust, Control, Relationship and Interaction. Meanwhile, the specific contradiction matrices, judgment matrices and strategy collections based on TRIZ are constructed which make the connotation of contradiction matrices in TRIZ extended. Finally they are applied to the construction of the collaborative model on enterprise network based on Multi Agent System (MAS).
\end{abstract}

Keywords: TRIZ, extended contradiction matrices, extended judgment matrices, strategy collections, collaborative model.

\section{Introduction}

Enterprise network is a special organization form which is different from market and hierarchy in enterprises and it is composed of independent enterprises through formal or informal contracts. All members in this organization are independent and sharing pains in corporation for a long time. Corporation and win-win is its core character; Meanwhile competitions between enterprises in network take place because they are independent. With the integration of global economy and swift development of science technology, more and more enterprises are to join in enterprise alliances, enterprise groups or virtue enterprises which are the existed enterprise network forms to meet the unknown, complicated future. Although the collaborative effects in enterprise network are confirmed in mass literature. Duhaime(2002) put forward the opinion that the collaborative effects are not born exist which means where there is enterprise network, there is not sure collaborative effects occur. Sharing the research costs, dispersing operation risks and strengthening core-competitiveness are all the expectations of each enterprise in the network. How to make the expectations come true? It is necessary to turn our mind to the enterprise network governance.

The related literature so far can be classified to two groups: One is about governance mechanism and collaborative mechanism which are more abstract and theoretical; The other is on relatively specific governance model or collaborative model. The former mainly has the following aspects: Series of JM(Johanson\&Mattson,1987)[1] 
model and taking some of trust, contract, theory of transaction cost, control, interaction, relationship as the study object. Series of JM model: Messner(2000) summed up three characters of networks as: parallel connected performance subjects, transorganization relationship and interaction between performance subjects which referred to the logic administration process of enterprise and can be considered to be supplement of JM model; Sun Guo-qiang(2003)[2] used the theory of system science to construct a triangle model of governance logic which combines the relationship, interaction and synergy, based on the extension of JM model, and then analyzed positively the typical correlation between enterprise networks governance mechanism and its effects through making a survey of 42 enterprises in 2005[3]. Researches taking some of trust, contract, transaction cost, interaction relationship as subject are as follows: YANG Rui-long(2003) used the theories of transaction cost and firm competence, and analysis how the asset specificity, firm competence, uncertainty influence the boundary of the firm[4]; Hao Chen(2005)] held the opinion that trust governance mechanism kept a close relationship with other relationship governance mechanism. Reputation is the source of trust :the better reputation one node makes, the more trust it will get. Zhang Bao-gui(2005) pointed out that the key of enterprise network's success was that whether the administration mechanism can guarantee each enterprise in it have a strong motivation not to take opportunism action but sync-interact and cooperate effectively although there is asymmetrical information and incomplete contacts; Zhang Yi(2005) put forward the concept of trust level in firm cooperation and analyzed the process of firm cooperation according to game theory. And then the effect of inter-firm trust level on firm decision was studied deeply, and the sufficient and necessary condition for firm cooperation was drawn that inter-firm trust level must exceed a critical value. Because there is a correlation in firm's repeated cooperation and inter-firm trust level acts as a signal transfer in firm cooperation, previous firm relation has a positive effect on sequential firm relation, which leads to successful firm cooperation in later time[5]; Liu Xue took China's pharmaceutical industry R\&D alliance as a sample, probed into the relationship between the initial trust before the conclusion of alliance and control strategy, and discovered that competence trust is positively correlative to process control and to self-safeguard control, that good will trust, on the contrary, is negatively correlative to outcome control and to selfsafeguard control, and that the uncertainty in technology plays a role in adjusting the correlation in impacting on the choice between trust and control strategies[6]; Su Zhong-feng (2007) discussed the influences of the control mechanisms on alliance's performance. The survey results indicated when and how to choose proper strategies to make alliance more effective[7]; On governance model, T.K.Das.\& Bing-Sheng Teng have some study on trust, control, risk and strategic alliances during 1997-2001: discussed systematically the various linkages between the different types of trust, control, and risk in alliances and suggested several risk reduction approachesminimizing relational risk through goodwill trust, behaviour control and social control, while minimizing performance risk through competence trust, output control, and social control. Finally, they developed propositions for empirical testing to the integrated framework [8]-[15]; BAO Yu-ling(2008)[16] researched the stackelberg gambling model of the cooperation through the suitable price discount strategy to 
improve achievement of the supply chain with different year demand, ordering cycle, ordering number of each time, as well as each time order quantity and so on; GUO Hong-lian(2008)[17] set up competitive \& cooperation game theory models whose objects are maximizing the profits of the three-hierarchy supply chain system and each node enterprise.

Above all, we know that the existed literature have done more contribution, and we can also refine that the main enterprise governance influence factors are: trust (25 times), control (33times), relationship (38times) and interaction (17times). However, there is so much work to do on its integration and focus. The contradiction matrices, judgment matrices and strategy collections based on TRIZ are tried to be constructed which makes the connotation of contradiction matrices in TRIZ extended. Finally they are applied to the construction of the collaborative model on enterprise network based on Multi Agent System (MAS). The integration and focus property of this paper playing a part in enterprise network governance's theory and practice is expected.

\section{Construction of the Extended Contradiction Matrices and Judgment Matrices Based on TRIZ}

Contradiction matrix is an important solving innovation problems tool in TRIZ, which is composed of 39*39 general engineering parameters and 40 innovation principles. The parameters in first longitudinal list are parameters expected better, and the parameters in first transverse are worse ones. Once the expected better parameters and worse parameters are confirmed, a couple of contradictions can be defined, and then we can find a group of corresponding innovation principles which form the possible solution collection. Contradiction matrix can eliminate the impossible solutions to the greatest extent and give the concentrated possible solutions which can give some product improving directions according to objective laws. Beside above, it can also avoid mass unnecessary trials, economize human power, resources, financial support. In this chapter, the extended contradiction matrices judgment matrices, and strategy collections based on TRIZ which are directed mainly at enterprise network collaborative process are tried to be constructed.

\subsection{Construction of the Extended Contradiction Matrices Based on TRIZ}

Trust, control, relationship and interaction are the four important influence factors according to mass literatures which has been analyzed in chapter 1 . We consider trust, control, relationship are all the specific actions of interaction, and collaboration effects are the result of interaction. So trust, control, relationship are defined the key contradiction factors in the contradiction matrix, interaction is considered as the process of collaboration in the model. The parameters in the first longitudinal list and first transverse list denote the key contradiction factors which one enterprise maintain are the important factors influencing its strategy with other enterprises in enterprise network. Once the enterprise defines the key influence factors, contradiction matrix $\mathrm{A}_{\mathrm{ij}}$ is defined. 
Table 1. The extended contradiction matrix based on TRIZ I

\begin{tabular}{cccc}
\hline Key Contradiction Factors & 1. Trust & 2. Control & 3. Relationship \\
\hline 1. Trust & A11 & A12 & A13 \\
2. Control & A21 & A22 & A23 \\
3. Relationship & A31 & A32 & A33 \\
\hline
\end{tabular}

Make $\mathrm{A}_{\mathrm{ij}}$ denote the secondary matrices which is composed of the $\mathrm{i}_{\mathrm{th}}$ contradiction factors and the $j_{t h}$ contradiction factors. We can get following results: (1) $A_{i j}=A_{j i}$, (2) $A_{i j}$ (i=j) (such as $A_{11}, A_{22}, A_{33}$ ) means that there is only one factor the enterprise assumes important for its strategy decision. In order to simulate the situation of enterprises dealing with strategy choice accurately, on one hand, the key contradiction factors are tried to be refined further; on the other hand, contradiction matrices will be quantized indistinctly. The judgment matrices and strategy collection will be constructed later.

1. Refining the dimensions of the key contradiction factors

According to the existed literature, refine trust to competence trust (CT)and goodwill trust(GT) dimensions(Barber,1983;Das\&Teng,2001);Divide control into formal control (FC) based on contracts and social control(SC) based on trust dimensions; Relationship will be described from continuity $(\mathrm{RC})$ and frequency(RF) dimensions.

1. Quantization

Details are shown as following tables.

Table 2. Trust dimension contradiction matrix based on TRIZ I-I (A11)

\begin{tabular}{cccc}
\hline Trust dimension & GT-high & GT-mid & GT-low \\
\hline CT-high & $\omega_{1}$ & $\omega_{4}$ & $\omega_{7}$ \\
CT-mid & $\omega_{2}$ & $\omega_{5}$ & $\omega_{8}$ \\
CT-low & $\omega_{3}$ & $\omega_{6}$ & $\omega_{9}$ \\
\hline
\end{tabular}

Table 3. Control Dimension Contradict Matrix based on TRIZ I-II(A22)

\begin{tabular}{cccc}
\hline Control Dimension & SC-high & SC-mid & SC-low \\
\hline FC-high & $\alpha_{1}$ & $\alpha_{4}$ & $\alpha_{7}$ \\
FC-mid & $\alpha_{2}$ & $\alpha_{5}$ & $\alpha_{8}$ \\
FC-low & $\alpha_{3}$ & $\alpha_{6}$ & $\alpha_{9}$ \\
\hline
\end{tabular}


Table 4. Relationship Dimension Contradict Matrix based on TRIZ I-III (A33)

\begin{tabular}{lccc}
\hline Relationship Dimension & RF-high & RF-mid & RF-low \\
\hline RC-high & $\beta_{1}$ & $\beta_{4}$ & $\beta_{7}$ \\
RC-mid & $\beta_{2}$ & $\beta_{5}$ & $\beta_{8}$ \\
RC-low & $\beta_{3}$ & $\beta_{6}$ & $\beta_{9}$ \\
\hline
\end{tabular}

\subsection{Construction of Judgment Matrix Based on TRIZ}

In this paper, $\mathrm{B}_{\mathrm{ij}}$ denotes the judgment matrices composed of vectors of the key contradiction factors. Once a couple of contradictions are defined, we can find a judgment matrix. There as a group of corresponding strategies which compose of contradictions' possible solutions collection. Take $\mathrm{A}_{12}$ for example, its key contradiction factors vectors are $\left[\alpha_{1}, \alpha_{2}, \ldots, \alpha_{9}\right],\left[\omega_{1}, \omega_{2}, \ldots, \omega_{9}\right]$, corresponding judgment matrix made of $\left[\alpha_{1}, \alpha_{2}, \ldots, \alpha_{9}\right] \mathrm{T},\left[\omega_{1}, \omega_{2}, \ldots, \omega_{9}\right]$ is refine as table 5 .

Table 5. Trust-Control Dimensions Judgment Matrix based on TRIZ

\begin{tabular}{llllllllll}
\hline $\mathrm{C} / \mathrm{T}$ & $\omega_{1}$ & $\omega_{2}$ & $\omega_{3}$ & $\omega_{4}$ & $\omega_{5}$ & $\omega_{6}$ & $\omega_{7}$ & $\omega_{8}$ & $\omega_{9}$ \\
\hline$\alpha_{1}$ & $\mathrm{~B}_{11}$ & $\mathrm{~B}_{12}$ & $\mathrm{~B}_{13}$ & $\mathrm{~B}_{14}$ & $\mathrm{~B}_{15}$ & $\mathrm{~B}_{16}$ & $\mathrm{~B}_{17}$ & $\mathrm{~B}_{18}$ & $\mathrm{~B}_{19}$ \\
$\alpha_{2}$ & $\mathrm{~B}_{21}$ & $\mathrm{~B}_{22}$ & $\mathrm{~B}_{23}$ & $\mathrm{~B}_{24}$ & $\mathrm{~B}_{25}$ & $\mathrm{~B}_{26}$ & $\mathrm{~B}_{27}$ & $\mathrm{~B}_{28}$ & $\mathrm{~B}_{29}$ \\
$\alpha_{3}$ & $\mathrm{~B}_{31}$ & $\mathrm{~B}_{32}$ & $\mathrm{~B}_{33}$ & $\mathrm{~B}_{34}$ & $\mathrm{~B}_{35}$ & $\mathrm{~B}_{36}$ & $\mathrm{~B}_{37}$ & $\mathrm{~B}_{38}$ & $\mathrm{~B}_{39}$ \\
$\alpha_{4}$ & $\mathrm{~B}_{41}$ & $\mathrm{~B}_{42}$ & $\mathrm{~B}_{43}$ & $\mathrm{~B}_{44}$ & $\mathrm{~B}_{45}$ & $\mathrm{~B}_{46}$ & $\mathrm{~B}_{47}$ & $\mathrm{~B}_{48}$ & $\mathrm{~B}_{49}$ \\
$\alpha_{5}$ & $\mathrm{~B}_{51}$ & $\mathrm{~B}_{52}$ & $\mathrm{~B}_{53}$ & $\mathrm{~B}_{54}$ & $\mathrm{~B}_{55}$ & $\mathrm{~B}_{56}$ & $\mathrm{~B}_{57}$ & $\mathrm{~B}_{58}$ & $\mathrm{~B}_{59}$ \\
$\alpha_{6}$ & $\mathrm{~B}_{61}$ & $\mathrm{~B}_{62}$ & $\mathrm{~B}_{63}$ & $\mathrm{~B}_{64}$ & $\mathrm{~B}_{65}$ & $\mathrm{~B}_{66}$ & $\mathrm{~B}_{67}$ & $\mathrm{~B}_{68}$ & $\mathrm{~B}_{69}$ \\
$\alpha_{7}$ & $\mathrm{~B}_{71}$ & $\mathrm{~B}_{72}$ & $\mathrm{~B}_{73}$ & $\mathrm{~B}_{74}$ & $\mathrm{~B}_{75}$ & $\mathrm{~B}_{76}$ & $\mathrm{~B}_{77}$ & $\mathrm{~B}_{78}$ & $\mathrm{~B}_{79}$ \\
$\alpha_{8}$ & $\mathrm{~B}_{81}$ & $\mathrm{~B}_{82}$ & $\mathrm{~B}_{83}$ & $\mathrm{~B}_{84}$ & $\mathrm{~B}_{85}$ & $\mathrm{~B}_{86}$ & $\mathrm{~B}_{87}$ & $\mathrm{~B}_{88}$ & $\mathrm{~B}_{89}$ \\
$\alpha_{9}$ & $\mathrm{~B}_{91}$ & $\mathrm{~B}_{92}$ & $\mathrm{~B}_{93}$ & $\mathrm{~B}_{94}$ & $\mathrm{~B}_{95}$ & $\mathrm{~B}_{96}$ & $\mathrm{~B}_{97}$ & $\mathrm{~B}_{98}$ & $\mathrm{~B}_{99}$ \\
\hline
\end{tabular}


We can know that there are 81 judgment matrix on Trust-Control dimensions $\mathrm{A}_{12}$ according to the table above(table 5). By inference, on Trust-Relationship dimensions there are 81 , on Control-Relationship dimensions there are 81 . Therefore, there are 243 judgment matrices.

\subsection{Constructing Strategy Collections of Corresponding Judgment Matrices}

Take $\mathrm{A}_{12}$ for example to analyze its corresponding strategy collection again. The methods of analyzing other dimensions are the same.

There are so many existed researches on trust and control and more are concentrated on theory study and some put forward some new conception, model or assumption. Rosalinde, Bas \& Bart(2005) held the idea that contracts will decline the chance and motivation of opportunism in the view of transaction cost theory and incomplete contracts theory. It is because that once enterprises take opportunism actions, they will paid for the laws cost. Thus, there is no choice for them but to keep honest. It comes to the conclusion that contracts and trust is positively related; contracts are the guarantee of trust. Some scholars held the opinion that control is not conductive to the construction of trust: Gaski (1984), Hunt \& Nevin(1974), Lusch (1976), (Goshal \& Moran, 1996) thought that formal control's over-using may provoke conflicts, opportunism actions (Goshal \& Moran, 1996) and self-safeguard (Zand, 1972; Hirschman, 1984). On the positive research, Anderson \& Narus (1990), Powell (1990), Zaheer \& Venkatraman (1995), Poppo \& Zenger (2002), LuoYadong (2002) came to a conclusion that high trust and formal control is complementary; some studies considered that trust is the precondition of contracts. (Larson, 1992; Ring \& Van de Van, 1992). Since Das \& Teng(1998) analyzed alliance characters in detail, constructed a conception model of alliance trust and control, which is based on the control frame put forward by Ouchi, some scholars (2001) took the joint venture alliances as study objects, found that goodwill trust and competence trust could both improve the effects of process control and results control which belongs to formal control conception. Local scholar Liu Xue made a investigation into pharmaceutical industry and came to a conclusion that process control would decline the positive correlation between trust and alliance performance and the trust level in the two sides of alliance is positive correlated with alliance performance. Thus, the strategy collection given in this article will be constructed mainly according to the existed related literatures such as the ones above. In the condition of $\omega_{1}$ (CT-high, GT-high), the corresponding judgment matrix are $\mathrm{Bi1}(\mathrm{i}=1,2, \ldots 9$ ), the corresponding strategy is keep the control level to low; when it is in the condition of $\omega_{2}$ (CT-mid, GT-high), the corresponding judgment matrix are $\mathrm{Bi} 2$ ( $\mathrm{i}=1,2, \ldots 9$.), the corresponding strategy is keep control level to midlow; in the condition of $\omega_{3}$ ( CT-low, GT-high), the corresponding judgment matrix are $\mathrm{Bi} 3(\mathrm{i}=1,2, \ldots 9$.), the corresponding strategy is to enforce process control in formal control; in the condition of $\omega_{4}$ (CT-high, GT-mid), the corresponding judgment matrix are $\mathrm{Bi} 4(\mathrm{i}=1,2, \ldots 9$.), the corresponding strategy is to keep action control mid; in the condition of $\omega_{5}$ (CT-mid, GT-mid), the corresponding judgment matrix are Bi5 
( $i=1,2, \ldots 9$.), the corresponding strategy is to keep control mid; in the condition of $\omega_{6}$ (CT-low, GT-mid), the corresponding judgment matrix are $\mathrm{Bi6}(\mathrm{i}=1,2, \ldots 9$.$) ,$ the corresponding strategy is to enforce formal control such as process control and action control; in the condition of $\omega_{7}$ (CT-high, GT-low), the corresponding judgment matrix are $\mathrm{Bi} 7(\mathrm{i}=1,2, \ldots 9$.$) , the corresponding strategy is to enforce results$ control in formal control; in the condition of $\omega_{8}$ ( CT-mid, GT-low), the corresponding judgment matrix are $\mathrm{Bi} 8(\mathrm{i}=1,2, \ldots 9$.$) , the corresponding strategy is to enforce$ results control and process control in formal control; in the condition of $\omega_{9}$ (CT-low, GT-low), the corresponding judgment matrix are $\mathrm{Bi} 9(\mathrm{i}=1,2, \ldots 9$.$) , the correspond-$ ing strategy is to choose a new partner.

\section{Construction of the Collaborative Model on Enterprise Networks Based on Multi Agent System (MAS)}

How a partner enterprise deals relationship with the other enterprises step by step is discussed in chapter2, 3. However, the final goals for an enterprise network are collaborative effects but not only a single enterprise get its optimum solution. It needs to take some actions to deal with the conflicts. In this chapter, several results will be defined firstly, and then, a collaborative model based on MAS will be constructed considering the contradiction matrices, judgment matrices and strategy collection which have been described already.

\section{Definition of Collaborative Result}

It is necessary to analyze different interest groups' different goals from different angles before defining the conception of Collaborative Result.

(1). In light of the whole enterprise network. When we consider the enterprise networks face t o markets as a whole, A whole optimal result will be the final measurement. For a given enterprise network, the whole optimal utility result is fixed. So we define the whole optimal solution as below:

$$
\mathrm{WOR}=\max _{s} \sum_{i=1}^{n} u_{i}(S)-c_{i}(S) \text {, }
$$

$S$ denotes vectors composed of different strategy variables in enterprise networks; $\boldsymbol{u}_{i}(S)$ denotes the utility which is achieved by enterprise i in the network; $\boldsymbol{C}_{i}(S)$ denotes the cost paid by enterprise $\mathrm{i}$ in the network using strategy $\mathrm{S}$.

(2). In light of a single enterprise in the network. As a single enterprise, its goal is "single satisfaction" while its utility is no less than its utility before joining in the 
collaborative network 's game playing Nash balance value $v_{0}=u_{i}(0)-c_{i}(0)$. It will be defined the deadline that a single enterprise can accept. All utilities of enterprises in the network form a vector with $\mathrm{n}$ dimensions, if and only if each branch vector of this vector is not ness than each corresponding branch vector of $v_{0}$, which also means $\boldsymbol{v}_{s}=\left(\boldsymbol{U}_{1}(s)-\boldsymbol{C}_{1}(s), \boldsymbol{U}_{2}(s)-\boldsymbol{C}_{2}(s), \ldots, \boldsymbol{U}_{n}(s)-\boldsymbol{C}_{n}(s)\right)$, and while $\boldsymbol{u}_{i}(s)-\boldsymbol{C}_{i}(s) \geq \boldsymbol{v}_{0}, \mathrm{i}=1,2, \ldots \mathrm{n}$, we called the vector $\boldsymbol{v}_{s}$ single satisfaction result.

(3). The original intension of the enterprise network and its eager for stability both make neither the whole optimal result nor the single satisfaction result the proper result destined. If the enterprise network demanded a longer, steady-going development, coordination must be done. The coordination actions will make the enterprise network achieve whole utility largest on the premise that each enterprise get its single satisfaction results at least. Now we call the $\mathrm{n}$ dimensions vector composed of each enterprise's utility collaborative result.

\section{Construction of the Collaborative Model}

In a typical enterprise network structure, there will be a core enterprise,and other enterprises focus on their own core-competitiveness; However, in some there is no core enterprise but an organization just like coordinating council; Even if there is no a core enterprise or an organization just like coordinating council, we can imagine one artificially which we call Administration Agent. One of its function is to take charge of making each enterprise in network harmonious. At the same time, Administration Agent will be responsible for choosing TRIZ Agent (Contradiction Matrix Agent, Judgment Matrix Agent, Strategy Collection Agent), dealing with it and feeding back data to each Enterprise Agent. In a word, the process of the collaborative effects coming true is the process of Administration Agent interacting with each Enterprise Agent. The collaborative model is figure 1.

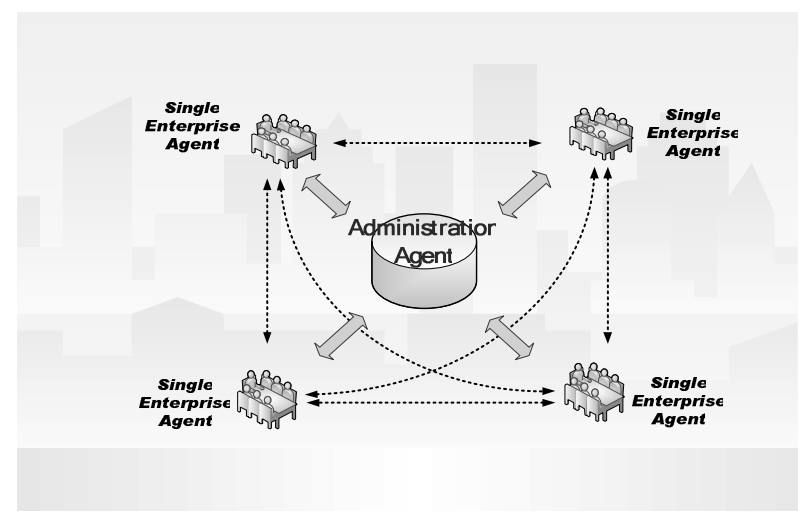

Fig. 1. Collaborative Model of Enterprise Network 
The core-structure of Administration Agent is shown in figure 2.

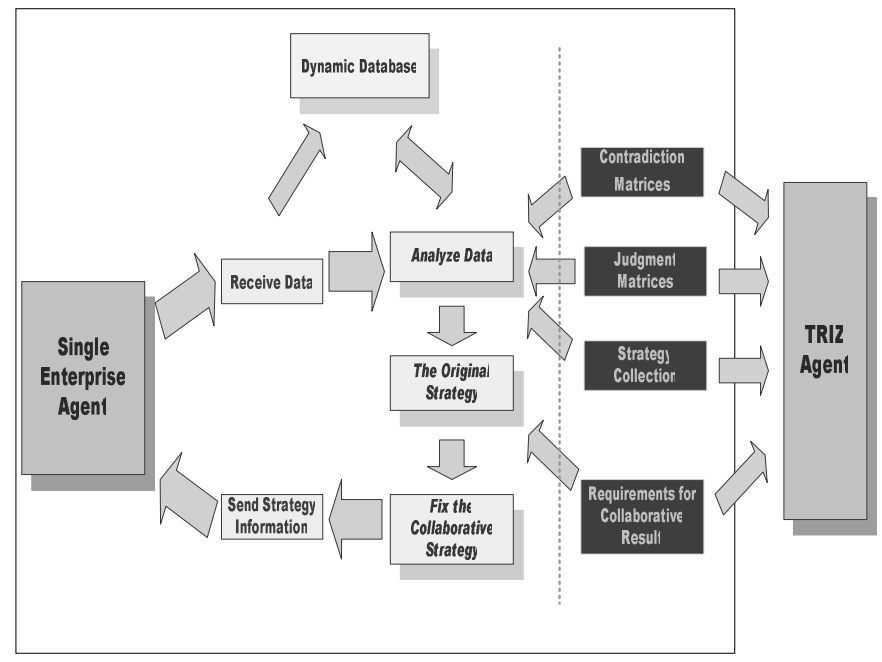

Fig. 2. The core structure of Administration Agent

Step 1. Receive each enterprise 's data.

Step 2. Send received data to dynamic data-base, and update the dynamic database continuously.

Step 3. Analyze the updating data and match the contradiction matrices, judgment matrices and strategy collection. Till now, the original strategies come to being.

Step 4. Compare the original strategy with collaborative result (collaborative result updates with dynamic database),and then adjust it to collaborative result's requirements.

Step 5. Fix the final collaborative strategy.

Step 6. Send strategy information to each enterprise Agent.

Thus, the administration agent performances just like an intangible hand using the frame of MAS which can provide mechanisms on communication, coordination and trigger fully. It makes the system can response to continuously varied data swift and right.

\section{Conclusion}

According to mass literatures, on the hand, the key influence factors of enterprise network are defined, and the extended contradiction matrices, judgment matrices and strategy collection are constructed base on TRIZ; on the other hand, deal with administration agent just like an intangible hand based on the frame of MAS. The enterprise network acquire collaborative effects finally by interacting with each enterprise agent continuously. In the later, we are to have some study on quantizing the extended contradiction matrices, judgment matrices, strategy collection based on TRIZ and try to combine the administration agent with CAI further. 


\section{Acknowledgments}

This paper is under the project 2007FY140400 supported by The technological basic special project of the Ministry of Science and 2008ZR0015 supported by soft science project of Science and Technology bureau of Sichuan province and 2008'New century talents plan" supported by Ministry of Education.

\section{References}

1. Johanson, J., Mattsson, L.G.: Inter-organizational Relations in Industrial Systems: A Network Approach Compared With The Transaction-cost Approach. J. International Studies of Management \& Organization, M. E. Sharpe Inc., 34-38 (1987)

2. Sun, G.-q.: Interaction and Synergy the Governance Logic of Network Organization. J. China Industrial Economy 11, 14-20 (2003)

3. Sun, G.-q.: The Efficient Frontier of Inter-firm Network: a Rethinking of Economic Organization Logic. J. Economic Management. New Management 12, 50-55 (2005)

4. Yang, R.-1., Feng, J.: The Efficient Frontier of Inter-firm Network: a Rethinking of Economic Organization Logic. J. China Industrial Economy 11, 5-13 (2003)

5. Zhang, Y., Shao, X.: Analysis on the mechanism of trust transfer in firm cooperation. J. Huazhong Univ. of Sci. \& Tech. (Nature Science Edition) 9, 132-134 (2005)

6. Liu, X., Liu, X.-f.: Analysis on the mechanism of trust transfer in firm cooperation. J. Management World 11, 90-100 (2006)

7. Su, Z.-f., En, X., Yuan, L.: The choice of the Control Mechanisms Based on Alliance's Motivation and Its Influence on Alliance's Performance: Evidence from China. J. Nankai Business Review 5, 4-11 (2007)

8. Das, T.K., Teng, B.: Risk types and inter-firm alliance strucutres. J. Journal of Management Studies 26, 459-475 (1996)

9. Das, T.K., Teng, B.: Sustaining strategic alliances:Options and guidelines. J. Journal of General Management 22(4), 49-64 (1997)

10. Das, T.K., Teng, B.: Between trust and control: developing confidence in partner cooperation in alliances. J. Academic of Management Review 23(3), 491-512 (1998)

11. Das, T.K., Teng, B.-S.: Trust,Control,and Risk in Strategic Alliances: An Integrated Framework. J. Organization Studies 22/2, 251-283 (2001)

12. Sitkin, S.B., Sutcliffe, K.M., Schroeder, R.G.: Distinguishing control from learning in total quality management: A contingency perspective. J. Academy of Management Review 19, 537-564 (1994)

13. Sitkin, S.B., Weingart, L.R.: Determinants of risky decision-making behavior: A test of the mediating role of risk perceptions and propensity. J. Academy of Management Journal 38, 1573-1592 (1995)

14. Argris, A.: Veracity and commitment: Coop0erative behavior in first-time collaborative ventures. J. Cooperative strategies, European perspectives 2, 215-241 (1997)

15. Chesbrough, H.R., Teece, D.J.: Organizing for innovation. J. Harvard Business Review 74(10), 65-73 (1996)

16. Bao, Y.-1.: The Stacklberg Gambling Analysis on Two-Tier Supply China Coordination of Many Retailers. J. Chinesse Journal of Management Science 16(3), 68-72 (2008)

17. Guo, H.-1., Hou, Y.-x., Yang, B.-h.: Competitive \& Cooperation Game-Theory Coordination Model of Three-Hierarchy Supply Chain with M suppliers, 1 Manufacture and N Retailors. J. Chinese Journal of Management Science 16(6), 54-60 (2008) 